\title{
THE
}

\section{Changing epidemiology of methicillin-resistant Staphylococcus aureus in the Veterans Affairs Healthcare System, 2002-2009}

Aisling R. Caffrey

University of Rhode Island, aisling_caffrey@uri.edu

L. LaPlante

University of Rhode Island, kerrylaplante@uri.edu

Follow this and additional works at: https://digitalcommons.uri.edu/php_facpubs

Terms of Use

All rights reserved under copyright.

\section{Citation/Publisher Attribution}

Caffrey, A. R. \& LaPlante, K. L. (2012). Changing Epidemiology of Methicillin-Resistant Staphylococcus aureus in the Veteran Affairs Healthcare System, 2002-2009. Infection, 40(3), 291-297. doi: 10.1007/ s15010-011-0232-3

Available at: http://dx.doi.org/10.1007/s15010-011-0232-3 
4 Aisling R. Caffrey, M.S., Ph.D. ${ }^{1,2}$ and Kerry L. LaPlante, Pharm.D. ${ }^{1,2,3^{*}}$

5

$6{ }^{1}$ Veterans Affairs Medical Center, Infectious Diseases Research Program, Providence, RI,

7 02908, United States

$8 \quad{ }^{2}$ University of Rhode Island, Department of Pharmacy Practice, Kingston, RI, 02881, USA

$9 \quad{ }^{3}$ Alpert Medical School of Brown University, Division of Infectious Diseases, Providence, RI, 10 02912, United States

11

12 *Corresponding Author: Kerry L. LaPlante, Pharm.D., Veterans Affairs Medical Center (151),

13 Research Building \#35; 830 Chalkstone Avenue; Providence, RI 02908, United States; office:

14 401.273.7100 x2339; fax: 401.457.3305; e-mail: KerryLaPlante@uri.edu

15

16 Presented in part at the $50^{\text {th }}$ Annual Interscience Conference on Antimicrobial Agents and

17 Chemotherapy (ICAAC), September 15, 2010, Boston, MA.

18

19 Abstract Count: 250; Word Count: 1,911

20

21 Keywords: methicillin-resistant Staphylococcus aureus; epidemiology; Veterans Affairs

22 Healthcare System; temporal trends 


\section{ABSTRACT}

\section{Purpose}

25 The epidemiology of infections caused by methicillin-resistant Staphylococcus aureus (MRSA)

26 is changing. Temporal trends and differences between healthcare settings must be described to

27 better predict future risk factors associated with this dangerous bacterial infection.

Methods

30 A national MRSA-infected cohort was identified from 2002 through 2009 in the Veterans Affairs

31 Healthcare System of the United States: hospital (HOS), long-term care (LTC), and outpatient

32 (OPT). We analyzed within-setting time trends using generalized linear mixed models and

33 between-setting differences with $\chi^{2}$ and Wilcoxon rank-sum tests.

\section{Results}

36 The incidence of $S$. aureus, methicillin-susceptible $S$. aureus, and MRSA infections increased

37 significantly over time in all three settings based on modeled annual percent changes $(\mathrm{p}<0.001)$.

38 MRSA incidence rates rose by 14\%, 10\%, and 37\% per year in the HOS, LTC, and OPT settings

39 respectively. Among 56,345 MRSA-infected patients, comorbidity burden was highest among

40 LTC inpatients $(n=4,427)$ and lowest among outpatients $(n=7,250)$, with an average absolute

41 difference in specific comorbidities of $+2 \%$ and $-7 \%$ respectively compared to HOS inpatients

$42(\mathrm{n}=44,668)$. Over time, there was a significant $(\mathrm{p} \leq 0.02)$ decrease in previous inpatient

43 admissions and surgeries (all settings); diabetes with complications and surgical site infections

44 (HOS, OPT); median length of stay and inpatient mortality (HOS, LTC). Alternatively, obesity,

45 chronic renal disease, and depression were more common between 2002 and 2009 ( $\mathrm{p} \leq 0.02)$. 


\section{Conclusions}

48 Over the past eight years, we observed significant changes in the epidemiology of MRSA

49 infections, including decreases in traditional MRSA risk factors, improvements in clinical

50 outcomes, and increases in other patient characteristics that may affect risk. 


\section{INTRODUCTION}

52 Over the past decade, substantial shifts in the molecular and clinical epidemiology of methicillin-

53 resistant Staphylococcus aureus (MRSA) infections have been reported [1-12]. Although MRSA

54 infections were once predominantly hospital-acquired, this insidious pathogen has evolved and is

55 now pervasive in communities across the United States (U.S.) [2-4]. Ensuing evidence has

56 documented the rise in community-associated MRSA (CA-MRSA) and decline in invasive

57 healthcare-associated MRSA (HA-MRSA), altering the distribution of attributed exposure and

58 onset, strain characteristics, and predominant infection types [1-12]. However, in this era of

59 epidemiologic change, knowledge of trends in patient characteristics is limited.

60

61 We therefore sought to describe the underlying patient populations infected with MRSA from

62 diverse healthcare settings of a single source population. Our objectives were to quantify

63 differences in patient demographics, comorbidities, clinical characteristics, and outcomes

64 between healthcare settings and describe within-setting changes over time among hospital

65 inpatients, long-term care inpatients, and outpatients in the national Veterans Affairs (VA)

66 Healthcare System.

67

68 METHODS

69 Study Design and Population. To describe the epidemiology of MRSA from January 1, 2002

70 through December 31, 2009, we utilized national databases documenting care provided by the

71 VA Healthcare System in the U.S. [13]. This retrospective, observational study identified

72 MRSA-infected adult patients ( $\geq 18$ years of age) from inpatient settings, consisting of hospital 
73 admissions and long-term care facility admissions, and the outpatient setting. This study was

74 reviewed and approved by the Providence VA Medical Center Institutional Review Board.

76 Incidence. We assessed changes in MRSA incidence rates over time in the context of

77 Staphylococcus aureus (S. aureus) infections. Utilizing International Classification of Diseases, $789^{\text {th }}$ Revision (ICD-9) diagnosis codes, we identified S. aureus infections (ICD-9 038.11, 038.12, 79 041.11, 041.12, 482.41, 482.42, V09.0), which were then categorized as methicillin-resistant 80 (038.12, 041.12, 482.42, V09.0), or methicillin-susceptible (MSSA) based on the absence of a

81 MRSA code [10]. The yearly incidence rate was calculated for each setting as the number of $S$.

82 aureus, MSSA, and MRSA-related hospitalizations, long-term care admissions, or outpatient 83 visits per 1,000 admissions or visits.

84

85 Characteristics of MRSA-Infected Patients. If patients had more than one MRSA-related 86 admission or visit during the study period, the first encounter was selected for inclusion.

87 Comorbidities were assessed from ICD-9 codes present during the MRSA-related admission/visit 88 and any inpatient admission or visit in the previous year $[14,15]$. Previous healthcare exposures, 89 including inpatient admissions and surgeries, were captured in the year prior to the MRSA90 related admission/visit. Infection type was categorized as bacteremia (ICD-9 038.11, 038.12, 91 790.7), endocarditis (421.0), skin and soft tissue infection (ICD-9 681-682, 528.3), surgical site 92 infection (998.5), osteomyelitis (730.0-730.2), and pneumonia (482-486) based on diagnoses 93 present during the MRSA-related admission/visit [10, 15]. 
Statistical Analyses. Differences in patient demographics, comorbidities, clinical characteristics, and outcomes between healthcare settings were analyzed with $\chi^{2}$ and Wilcoxon rank-sum tests for categorical and continuous variables respectively. Within healthcare settings, we assessed the significance of temporal trends over the study years using generalized linear mixed models. Due to changes in coding practices, sensitivity analyses were carried out excluding MRSA-infected patients diagnosed in 2009. A p-value of $<0.05$ was considered statistically significant and all analyses were performed using SAS (SAS Institute Inc., Cary, NC, Version 9.2).

\section{RESULTS}

The incidence of S. aureus, MSSA, and MRSA infections increased significantly over time in all three settings based on modeled annual percent changes $(\mathrm{p}<0.001)$. MRSA-related hospitalizations increased from 6.7 in 2002 to 15.9 in 2009, from 8.3 to 15.9 MRSA-related long-term care admissions, and from 0.01 to 0.08 MRSA-related outpatient clinic visits per 1,000 admissions/visits (Fig 1). MRSA incidence rates increased annually by $37 \%$ in the outpatient setting, $10 \%$ in long-term care, and $14 \%$ in hospitals. Similarly, modeled MSSA incidence rates rose each year by $18 \%$ in the outpatient setting, $4 \%$ in long-term care, and $4 \%$ in hospitals. We observed a $4 \%$ increase per year in the modeled incidence for S. aureus-related long-term care admissions, a 5\% increase per year for hospital admissions, and a 21\% increase per year for outpatient visits. Sensitivity analyses demonstrated agreement, with the exception of nonsignificant changes over time in MSSA incidence for the hospital and long-term care settings. 
117 MRSA-infected long-term care inpatients $(n=4,427)$ and outpatients $(n=7,250)$ differed

118 significantly $(\mathrm{p} \leq 0.035)$ from those hospitalized $(\mathrm{n}=44,668)$ on most characteristics assessed

119 including demographics, comorbidities, previous healthcare exposures, and infection type (Table

120 1). Comorbidity burden was highest among MRSA-infected long-term care inpatients and

121 lowest among outpatients, with an average absolute difference in specific comorbidities of $+2 \%$

122 and -7\% respectively compared to hospital inpatients. Skin and soft tissue infections were the

123 most commonly reported infection type in each healthcare setting (hospital 31\%; long-term care

124 18\%; outpatient 23\%), followed by pneumonia among inpatients (hospital 16\%; long-term care

$12516 \%$ ) and osteomyelitis among outpatients (4\%). Endocarditis was reported in less than 1\% of

126 the MRSA-infected cohort and site of infection could not be determined from diagnosis codes in

127 33\% of patients (hospital 29\%; long-term care 34\%; outpatient 56\%) [10, 15].

128

129 Over time, the median Charlson Comorbidity Index changed significantly only among MRSA-

130 infected outpatients, decreasing from 3 in 2002 to 1 in 2009 (p=0.034). Temporal trends within

131 healthcare settings are presented in Table 2. Significant decreases $(p \leq 0.037)$ were observed in

132 the modeled annual percent change of MRSA-infected patients with cerebrovascular disease

133 (hospital 0.4\%; long-term care 0.8\%), diabetes with complications (hospital 0.4\%; outpatient

134 1.7\%), dialysis (hospital 0.2\%), and peripheral vascular disease (hospital 0.6\%; outpatient 1.8\%).

135 Inpatient admissions and surgeries in the year prior to the MRSA-related admission/visit were

136 significantly ( $\mathrm{p} \leq 0.02$ ) less common over time in all three settings (hospital 2.3\% and 1.8\%; long-

137 term care $0.9 \%$ and $1.3 \%$; outpatient $3.4 \%$ and $2.4 \%$ ). Alternatively, in each healthcare setting,

138 obesity and depression were more commonly reported from 2002 through 2009 in MRSA- 
139 infected patients $(\mathrm{p} \leq 0.02$; hospital $1.4 \%$ and $1.2 \%$; long-term care $1.2 \%$ and $1.7 \%$; outpatient $140 \quad 1.1 \%$ and $1.0 \%)$.

141

142 Non-significant increases were observed in skin and soft tissue infections over the study period

143 in all three settings. Among MRSA-infected long-term care inpatients, infection type was

144 relatively unchanged over time, except for a significant decrease $(\mathrm{p}<0.001)$ in pneumonia $(1.5 \%$

145 modeled annual percent change). Surgical site infections and osteomyelitis decreased

146 significantly each year among hospital inpatients and outpatients (hospital 0.6\% and 0.6\%;

147 outpatient $0.4 \%$ and $1.4 \%$ ), while pneumonia increased $1.2 \%$ per year in the hospital setting.

148 Among MRSA-infected inpatients, annualized decreases in median length of stay (hospital: 11

149 days in 2002 to 6 days in 2009; long-term care: 52 days to 36 days) and inpatient mortality

150 (hospital 0.9\%; long-term care 1.7\%) were significant $(\mathrm{p} \leq 0.01)$. Changes in patient

151 characteristics over time were similar in sensitivity analyses including data from 2002 through

1522008.

153

154 DISCUSSION

155 Our research uniquely assessed a comprehensive set of patient characteristics in three distinct

156 clinical settings of a nationwide healthcare provider, with a well-defined source population, in 157 the US. From this large, national epidemiologic study, significant increases in MRSA incidence 158 rates were discerned over the past eight years in the VA Healthcare System. Our findings are 159 similar to other national studies that have described rising MRSA incidence rates over the past 160 decade among children and adults in the U.S. and Canada [6, 10, 16]. Unlike the diverse 
161 healthcare settings we evaluated, these other studies were restricted to a single clinical setting,

162 specifically hospitals $[6,10,16]$.

164 In both the hospital and long-term care settings, we observed non-significant declines in MRSA

165 incidence rates between 2008 and 2009. The interaction of several contributing factors may

166 explain these reduced rates. VA infection control policies targeting MRSA were enhanced under

167 a nationwide directive, with full implementation in acute care facilities by December 31, 2007

168 and expansion to other healthcare settings during 2009 [17]. The MRSA Prevention Initiative

169 established active MRSA colonization surveillance and emphasizes contact precautions, hand

170 hygiene, and cultural transformation as components of the overall MRSA prevention bundle,

171 broadening infection control awareness through education $[17,18]$.

172

173 Additionally, the introduction of new diagnosis codes for MRSA infections may have impacted

174 coding practices. Previously, MRSA could only be coded as a secondary diagnosis (V09.0),

175 however primary ICD-9 codes for MRSA bacterial infection (041.12), MRSA septicemia

176 (038.12), and MRSA pneumonia (482.42) were adopted in 2009. Lastly, shifts in MRSA

177 exposure and onset likely played a role in the recent decline, as CA-MRSA has gained a larger

178 share of MRSA infections with subsequent reductions in HA-MRSA [2-5]. Active laboratory

179 surveillance in 9 U.S. metropolitan areas revealed substantial yearly rate decreases in the

180 incidence of invasive HA-MRSA infections from 2005 through 2008 [5]. We suspect the decline

181 we observed in hospital MRSA incidence was considerably less than the reported HA-MRSA

182 rate drop due to increases in invasive infections requiring inpatient care caused by CA-MRSA

183 [1-5]. 
185 As expected, MRSA-infected long-term care inpatients had a higher comorbidity burden than

186 hospital inpatients, and those hospitalized were in poorer health than outpatients. In quantifying

187 differences between healthcare settings, we found most comorbidities differed by several

188 percentage points comparing hospitalized and long-term care inpatients, although this difference

189 was more pronounced between outpatients and hospital inpatients.

190

191 In regards to temporal trends among patients infected with MRSA, we observed significant

192 declines in previously established MRSA risk factors, including diabetes with complications [19-

193 21], previous hospitalization [7, 20, 21], previous surgery [23], and dialysis [17, 22, 23]. Also

194 significant over time were increases in obesity and depression. Possible explanations for these

195 increases include changes in the underlying patient population infected with MRSA in the VA

196 Healthcare System, increased awareness and reporting, or the potential for these diseases to

197 affect the risk of developing MRSA infections. Overall, MRSA-infected patients appeared

198 healthier over the study period in each of the three settings and clinical outcomes improved. Our

199 findings are consistent with rising rates of CA-MRSA and the distinct clinical epidemiology of

200 CA-MRSA [2-5, 24].

201

202 A considerable limitation in our study and several others [10, 25, 26], is the use of diagnosis

203 codes to identify MRSA infections. Due to the lack of microbiology research databases in U.S.

204 healthcare systems, we are limited to diagnosis codes extracted from administrative data and

205 electronic medical records [10, 13, 25, 26]. Until health informatics advancements are made to 
extract and link such data, the only way to ascertain MRSA trends in large populations is with diagnosis codes.

Similar to other research using diagnosis codes, we could only determine site of infection in twothirds of the cohort [10]. This may explain the absence of significant increases in MRSA skin and soft tissue infections over time. Three of the MRSA diagnosis codes await validation as they were recently implemented (038.12, 041.12, 482.42). The original MRSA diagnosis code (V09.0) has suboptimal sensitivity but a high positive predictive value, indicating underascertainment $[10,27,28]$. It is important to note that coding accuracy in VA databases is reportedly higher than other healthcare systems [29, 30]. Further, sensitivity has been found to increase with greater numbers of available diagnosis code entries, which is relatively high in the VA databases (13 entries per admission plus 5 per bed section, 10 per outpatient visit) [10, 13, 27, 28]. The generalizability of the findings should be interpreted in the context of our source population, comprising 5.5 million patients treated annually by the VA Healthcare System, which is the largest integrated healthcare system in the country.

In conclusion, MRSA incidence rates rose significantly over the past eight years in the VA Healthcare System. We observed significant changes in the epidemiology of MRSA infections among hospital inpatients, long-term care inpatients, and outpatients from the same source population. Over time, MRSA-infected patients appeared healthier, with fewer exposures to MRSA risk factors and improved clinical outcomes, suggesting CA-MRSA has gained considerable ground in the VA Healthcare System nationally. 
228 ACKNOWLEDGEMENTS

229 We gratefully acknowledge the Center on Systems, Outcomes \& Quality in Chronic Disease \&

230 Rehabilitation, a Research Enhancement Award Program of the Health Services Research \&

231 Development Service, Providence Veterans Affairs Medical Center Research Service for data

232 storage and software assistance.

233

234 The views expressed are those of the authors and do not necessarily reflect the position or policy 235 of the United States Department of Veterans Affairs.

236

237 ARC is supported by a Department of Veterans Affairs Career Development Award.

238

239 FUNDING

240 This work was unfunded.

241

242 POTENTIAL CONFLICTS OF INTEREST

243 ARC: Pfizer research funding; KLL: Astellas, Cubist, Forest, Ortho-McNeil, and Pfizer research

244 funding, advisory board, speakers bureau, and/or consultancy. 


\section{REFERENCES}

1. Seybold U, Kourbatova EV, Johnson JG, Halvosa SJ, Wang YF, King MD, et al. Emergence of community-associated methicillin-resistant Staphylococcus aureus USA300 genotype as a major cause of health care-associated blood stream infections. Clin Infect Dis. 2006;42:647-56.

2. Van De Griend P, Herwaldt LA, Alvis B, DeMartino M, Heilmann K, Doern G, et al. Community-associated methicillin-resistant Staphylococcus aureus, Iowa, USA. Emerg Infect Dis. 2009;15:1582-9.

3. Limbago B, Fosheim GE, Schoonover V, Crane CE, Nadle J, Petit S, et al. Characterization of methicillin-resistant Staphylococcus aureus isolates collected in 2005 and 2006 from patients with invasive disease: a population-based analysis. J Clin Microbiol. 2009;47:1344-51.

4. Klevens RM, Morrison MA, Nadle J, Petit S, Gershman K, Ray S, et al. Invasive methicillin-resistant Staphylococcus aureus infections in the United States. JAMA. 2007;298:1763-1771.

5. Kallen AJ, Mu Y, Bulens S, Reingold A, Petit S, Gershman K, et al. Health careassociated invasive MRSA infections, 2005-2008. JAMA. 2010;304:641-8.

6. Simor AE, Gilbert NL, Gravel D, Mulvey MR, Bryce E, Loeb M, et al. Methicillinresistant Staphylococcus aureus colonization or infection in Canada: National Surveillance and Changing Epidemiology, 1995-2007. Infect Control Hosp Epidemiol. 2010;31:348-56. 
7. McCarthy NL, Sullivan PS, Gaynes R, Rimland D. Risk factors associated with methicillin resistance among Staphylococcus aureus infections in veterans. Infect Control Hosp Epidemiol. 2010;31:36-41.

8. Hersh AL, Chambers HF, Maselli JH, Gonzales R. National trends in ambulatory visits and antibiotic prescribing for skin and soft-tissue infections. Arch Intern Med. 2008;168:1585-91.

9. Edelsberg J, Taneja C, Zervos M, Haque N, Moore C, Reyes K, et al. Trends in US hospital admissions for skin and soft tissue infections. Emerg Infect Dis. 2009;15:1516-8.

10. Gerber JS, Coffin SE, Smathers SA, Zaoutis TE. Trends in the incidence of methicillinresistant Staphylococcus aureus infection in children's hospitals in the United States. Clin Infect Dis. 2009;49:65-71.

11. Meyer E, Ziegler R, Mattner F, Schwab F, Gastmeier P, Martin M. Increase of patients co-colonised or co-infected with methicillin-resistant Staphylococcus aureus, vancomycin-resistant Enterococcus faecium or extended-spectrum beta-lactamaseproducing Enterobacteriaceae. Infection. 2011 Jun 28. [Epub ahead of print].

12. Rosenthal VD, Maki DG, Jamulitrat S, Medeiros EA, Todi SK, Gomez DY, et al. International Nosocomial Infection Control Consortium (INICC) report, data summary for 2003-2008, issued June 2009. Am J Infect Control. 2010;38:95-104 e2.

13. Maynard C, Chapko MK. Data resources in the Department of Veterans Affairs. Diabetes Care. 2004;27(Suppl 2):B22-6.

14. Quan H, Sundararajan V, Halfon P, Fong A, Burnand B, Luthi JC, et al. Coding algorithms for defining comorbidities in ICD-9-CM and ICD-10 administrative data. Med Care. 2005;43:1130-9. 
15. Agency for Healthcare Research and Quality. Clinical Classifications Software (CCS), Healthcare Cost and Utilization Project (HCUP). Rockville, MD: Agency for Healthcare Research and Quality; 2010.

16. Klein E, Smith DL, Laxminarayan R. Hospitalizations and deaths caused by methicillinresistant Staphylococcus aureus, United States, 1999-2005. Emerg Infect Dis. 2007;13:1840-6.

17. U.S. Department of Veterans Affairs, Veterans Health Administration. MethicillinResistant Staphylococcus aureus (MRSA) Initiative, VHA Directive 2007-002. Washington, DC: U.S. Department of Veterans Affairs, Veterans Health Administration; 2007.

18. Garcia-Williams AG, Miller LJ, Burkitt KH, Cuerdon T, Jain R, Fine MJ, et al. Beyond beta: lessons learned from implementation of the Department of Veterans Affairs Methicillin-Resistant Staphylococcus aureus Prevention Initiative. Infect Control Hosp Epidemiol. 2010;31:763-5.

19. Laupland KB, Ross T, Gregson DB. Staphylococcus aureus bloodstream infections: risk factors, outcomes, and the influence of methicillin resistance in Calgary, Canada, 20002006. J Infect Dis. 2008;198:336-43.

20. Stenstrom R, Grafstein E, Romney M, Fahimi J, Harris D, Hunte G, et al. Prevalence of and risk factors for methicillin-resistant Staphylococcus aureus skin and soft tissue infection in a Canadian emergency department. CJEM. 2009;11:430-8.

21. Salangsang JA, Harrison LH, Brooks MM, Shutt KA, Saul MI, Muto CA. Patientassociated risk factors for acquisition of methicillin-resistant Staphylococcus aureus in a tertiary care hospital. Infect Control Hosp Epidemiol. 2010;31:1139-47. 
22. Shorr AF, Zilberberg MD, Micek ST, Kollef MH. Prediction of infection due to antibiotic-resistant bacteria by select risk factors for health care-associated pneumonia. Arch Intern Med. 2008;168:2205-10.

23. Maclayton DO, Suda KJ, Coval KA, York CB, Garey KW. Case-control study of the relationship between MRSA bacteremia with a vancomycin MIC of 2 microg/mL and risk factors, costs, and outcomes in inpatients undergoing hemodialysis. Clin Ther. 2006;28:1208-16.

24. Crum NF, Lee RU, Thornton SA, Stine OC, Wallace MR, Barrozo C, et al. Fifteen-year study of the changing epidemiology of methicillin-resistant Staphylococcus aureus. Am J Med. 2006;119:943-51.

25. Sircar KD, Bancroft E, Nguyen DM, Mascola L. Hospitalization of paediatric patients for methicillin-resistant Staphylococcus aureus skin and soft-tissue infection, 1998-2006. Epidemiol Infect. 2010;138:677-82.

26. Kuehnert MJ, Hill HA, Kupronis BA, Tokars JI, Solomon SL, Jernigan DB. Methicillinresistant-Staphylococcus aureus hospitalizations, United States. Emerg Infect Dis. 2005;11:868-72.

27. Schaefer MK, Ellingson K, Conover C, Genisca AE, Currie D, Esposito T, et al. Evaluation of International Classification of Diseases, Ninth Revision, Clinical Modification Codes for reporting methicillin-resistant Staphylococcus aureus infections at a hospital in Illinois. Infect Control Hosp Epidemiol. 2010;31:463-468.

28. Schweizer ML, Eber MR, Laxminarayan R, Furuno JP, Popovich KJ, Hota B, et 
al. Validity of ICD-9-CM coding for identifying incident methicillin-resistant Staphylococcus aureus (MRSA) infections: is MRSA infection coded as a chronic disease? Infect Control Hosp Epidemiol. 2011;32:148-154.

29. Singh JA, Holmgren AR, Noorbaloochi S. Accuracy of Veterans Administration databases for a diagnosis of rheumatoid arthritis. Arthritis Rheum. 2004;51:952-7.

30. Kern EF, Maney M, Miller DR, Tseng CL, Tiwari A, Rajan M, et al. Failure of ICD-9CM codes to identify patients with comorbid chronic kidney disease in diabetes. Health Serv Res. 2006;41:564-80. 


\section{TABLES}

Table 1. Demographics, comorbidities, clinical characteristics, and outcomes by healthcare setting among MRSA-infected patients in the Veterans Affairs Healthcare System

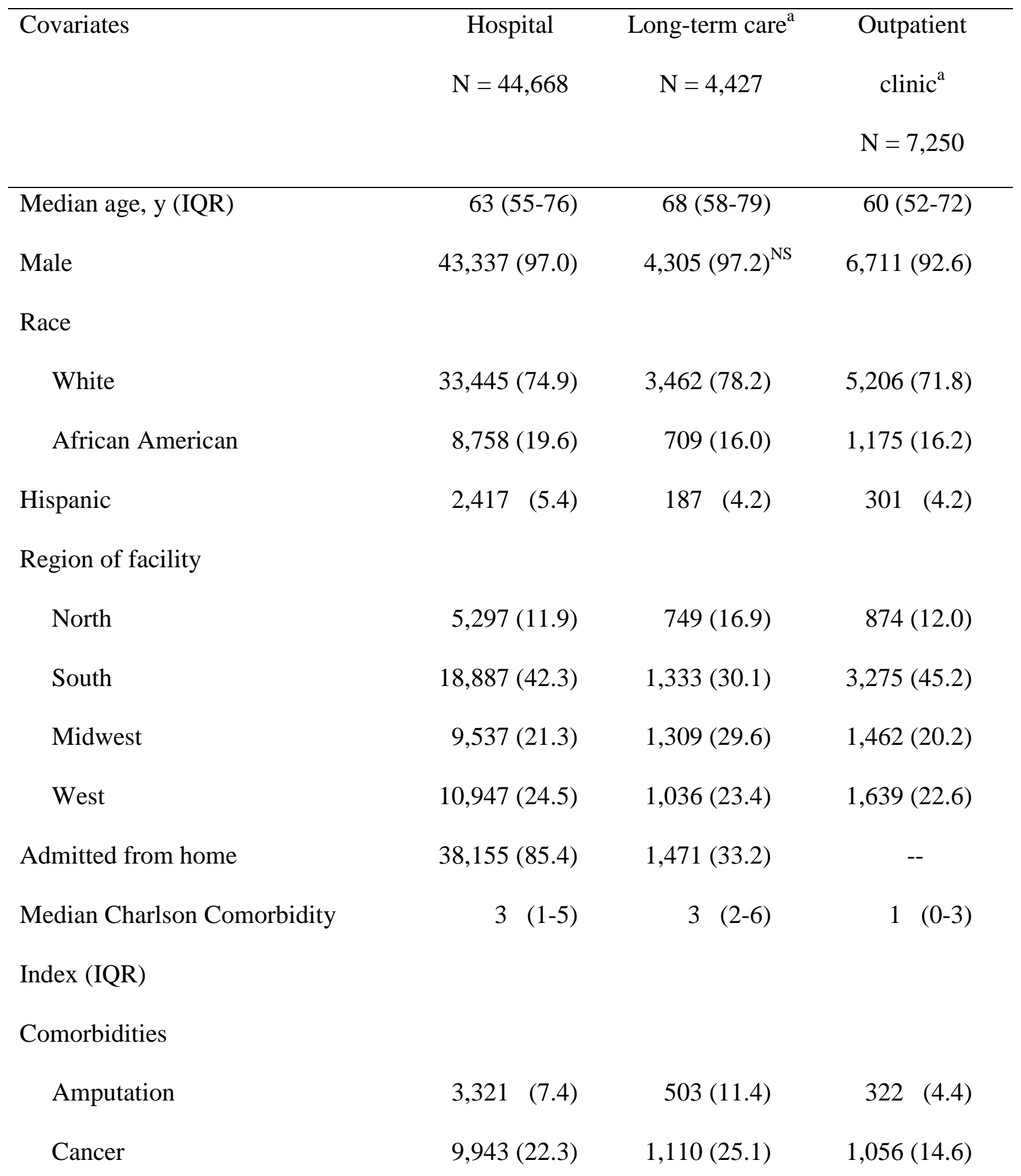


Cerebrovascular disease

Chronic renal disease

Chronic respiratory disease

Congestive heart failure

Depression

Diabetes

Diabetes with complications

Dialysis

Hypertension

Obesity

Paralysis

Peripheral vascular disease

Previous healthcare exposures

Inpatient admission

Surgery

Infection type

Bacteremia

Skin and soft tissue

Surgical site infection

Osteomyelitis

Pneumonia

Outcomes

Inpatient mortality

$\begin{array}{rrr}7,441(16.7) & 960(21.7) & 631(8.7) \\ 9,438(21.1) & 921(20.8)^{\mathrm{NS}} & 775(10.7) \\ 15,925(35.7) & 1,688(38.1) & 1,683(23.2) \\ 10,588(23.7) & 1,127(25.5) & 796(11.0) \\ 15,219(34.1) & 1,813(41.0) & 2,322(32.0) \\ 19,092(42.7) & 1,965(44.4) & 2,503(34.5)\end{array}$

$9,238(20.7) \quad 1,032(23.3) \quad 1,010(13.9)$

$1,517 \quad(3.4) \quad 142 \quad(3.2)^{\mathrm{NS}} \quad 87 \quad(1.2)$

$31,925(71.5) \quad 3,304(74.6) \quad 4,474(61.7)$

6,945 (15.5) $\quad 597(13.5) \quad 1,292(17.8)$

$3,130 \quad(7.0) \quad 310 \quad(7.0)^{\mathrm{NS}} \quad 177 \quad(2.4)$

$9,320(20.9) \quad 1,136(25.7)$

919 (12.7)
$27,408(61.4) \quad 3,630(82.0) \quad 2,211(30.5)$

$9,214(20.6) \quad 1,493(33.7) \quad 694 \quad(9.6)$

191 (2.6)

1,656 (22.8)

13,892 (31.1) $\quad 805(18.2) \quad 1,656(22.8)$

$2,803 \quad(6.3) \quad 343 \quad(7.8) \quad 186 \quad(2.6)$

$4,022 \quad(9.0) \quad 524(11.8) \quad 255 \quad$ (3.5)

$7,149(16.0) \quad 696(15.7)^{\mathrm{NS}} \quad 141$

$2,701(6.0) \quad 1,006(22.7)$ 
Follow-up MRSA admission

Median length of stay, d (IQR)
$27,731(62.1)$

$7(4-15)$
$2,236(50.5)$

$2,427(33.5)$

$45(21-105)$

Data are no. (\%), unless otherwise indicated. MRSA, methicillin-resistant Staphylococcus aureus; IQR, interquartile range; NS, non-significant.

${ }^{\text {a }}$ For all covariates, differed significantly compared to MRSA-infected hospitalized patients $(\mathrm{p} \leq 0.035)$, unless otherwise indicated (NS). Determined from $\chi^{2}$ or Wilcoxon Rank-Sum tests as appropriate. 
Table 2. Temporal trends in demographics, comorbidities, clinical characteristics, and outcomes by healthcare setting among MRSA-infected patients in the Veterans Affairs Healthcare System

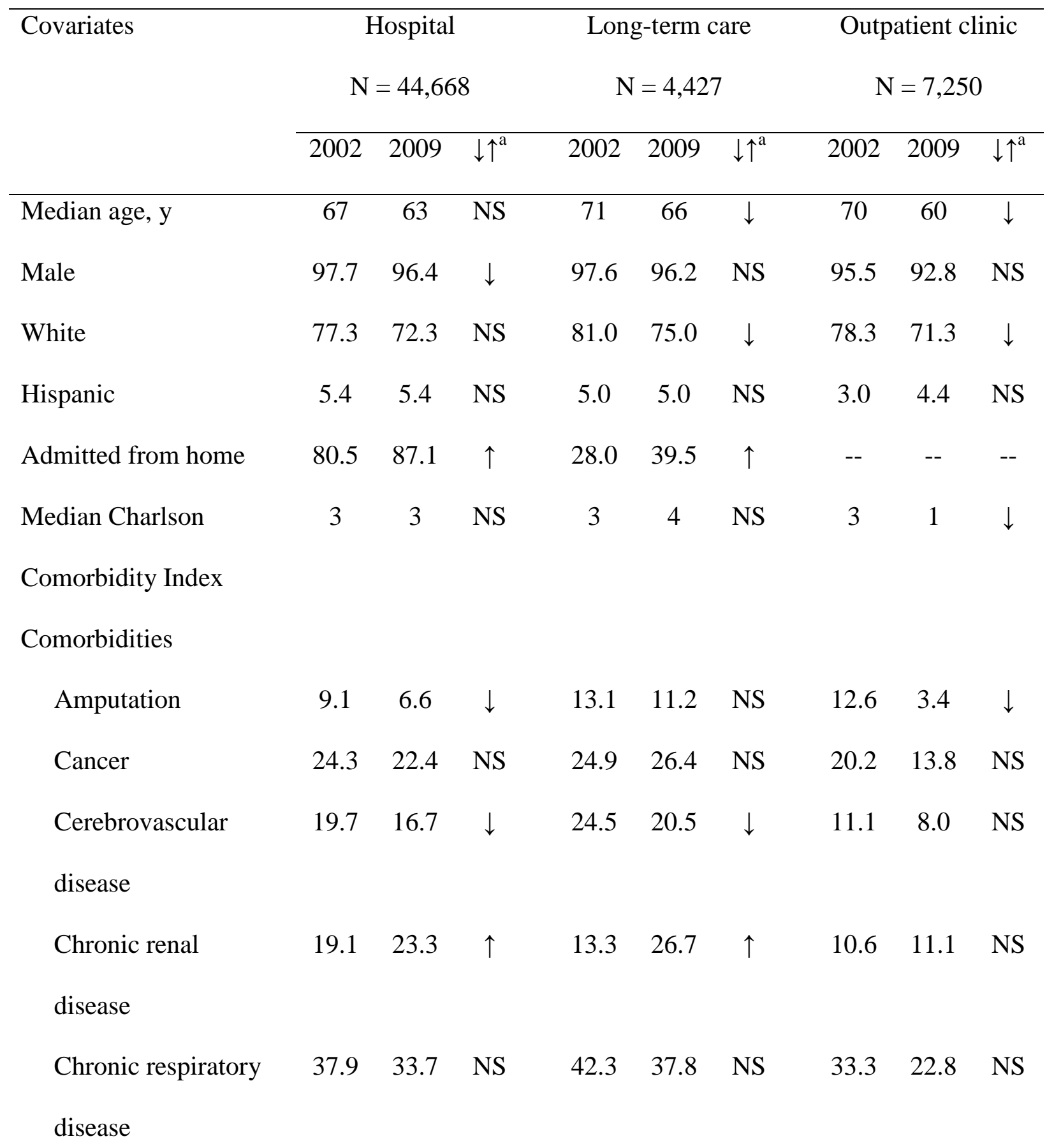


$\begin{array}{lllllllllll}\text { Congestive heart } & 26.5 & 22.5 & \text { NS } & 27.3 & 26.9 & \text { NS } & 19.2 & 9.6 & \downarrow\end{array}$ failure

Depression

Diabetes

Diabetes with

complications

Dialysis

Hypertension

Obesity

Paralysis

Peripheral vascular

disease

Previous healthcare

exposures

Inpatient admission

Surgery

Infection type

Bacteremia

18.0

$\begin{array}{lll}4.7 & 3.2 \quad \downarrow\end{array}$

$66.375 .5 \uparrow$

$10.0 \quad 18.7 \uparrow \uparrow$

$9.0 \quad 6.3 \downarrow$

$25.519 .7 \downarrow$

$15.1 \downarrow$ $\begin{array}{lll}4.0 & 3.6 & \text { NS }\end{array}$

$67.2 \quad 80.0 \uparrow$

$9.3 \quad 18.6 \uparrow$

$\begin{array}{lll}9.3 & 6.7 \quad \text { NS }\end{array}$

$24.0 \quad 27.6 \quad$ NS
$26.8 \quad 35.2 \uparrow$

$42.4 \quad 33.1 \quad \downarrow$

$22.7 \quad 12.6 \quad \downarrow$

Skin and soft tissue

$22.9-32.0$

$10.9 \quad 12.2 \quad$ NS

$2.5 \quad 3.0 \quad$ NS

Skin and soft tissue

22.9

$32.0 \quad$ NS

$15.0 \quad 16.2$ NS

$15.2 \quad 21.0 \quad$ NS

Surgical site

$8.7 \quad 5.5 \quad \downarrow$

$\begin{array}{lll}8.8 & 7.2 & \text { NS }\end{array}$

$5.1 \quad 1.4 \quad \downarrow$

infection

Osteomyelitis

$11.4 \quad 8.4 \quad \downarrow$

$\begin{array}{lll}9.5 & 10.3 & \text { NS }\end{array}$

12.6

Pneumonia

$\begin{array}{llllllllll}19.8 & 11.3 & \downarrow & 20.7 & 9.0 & \downarrow & 2.0 & 2.2 & \text { NS }\end{array}$




\section{Outcomes}

$\begin{array}{lcccccccccc}\text { Inpatient mortality } & 9.9 & 4.1 & \downarrow & 28.7 & 17.4 & \downarrow & -- & -- & -- \\ \text { Follow-up MRSA } & 68.3 & 46.2 & \downarrow & 54.2 & 32.9 & \text { NS } & 62.1 & 21.9 & \downarrow \\ \text { admission } & & & & & & & & & \\ \text { Median length of } & 11 & 6 & \downarrow & 52 & 36 & \downarrow & -- & -- & -- \\ \text { stay, d } & & & & & & & & \end{array}$

Data are \%, unless otherwise indicated. MRSA, methicillin-resistant Staphylococcus aureus; NS, non-significant.

${ }^{\text {a }}$ Increased $(\uparrow)$ or decreased $(\downarrow)$ significantly over time $(\mathrm{p} \leq 0.037)$, unless otherwise indicated (NS), as determined from generalized linear mixed models. 


\section{FIGURE}
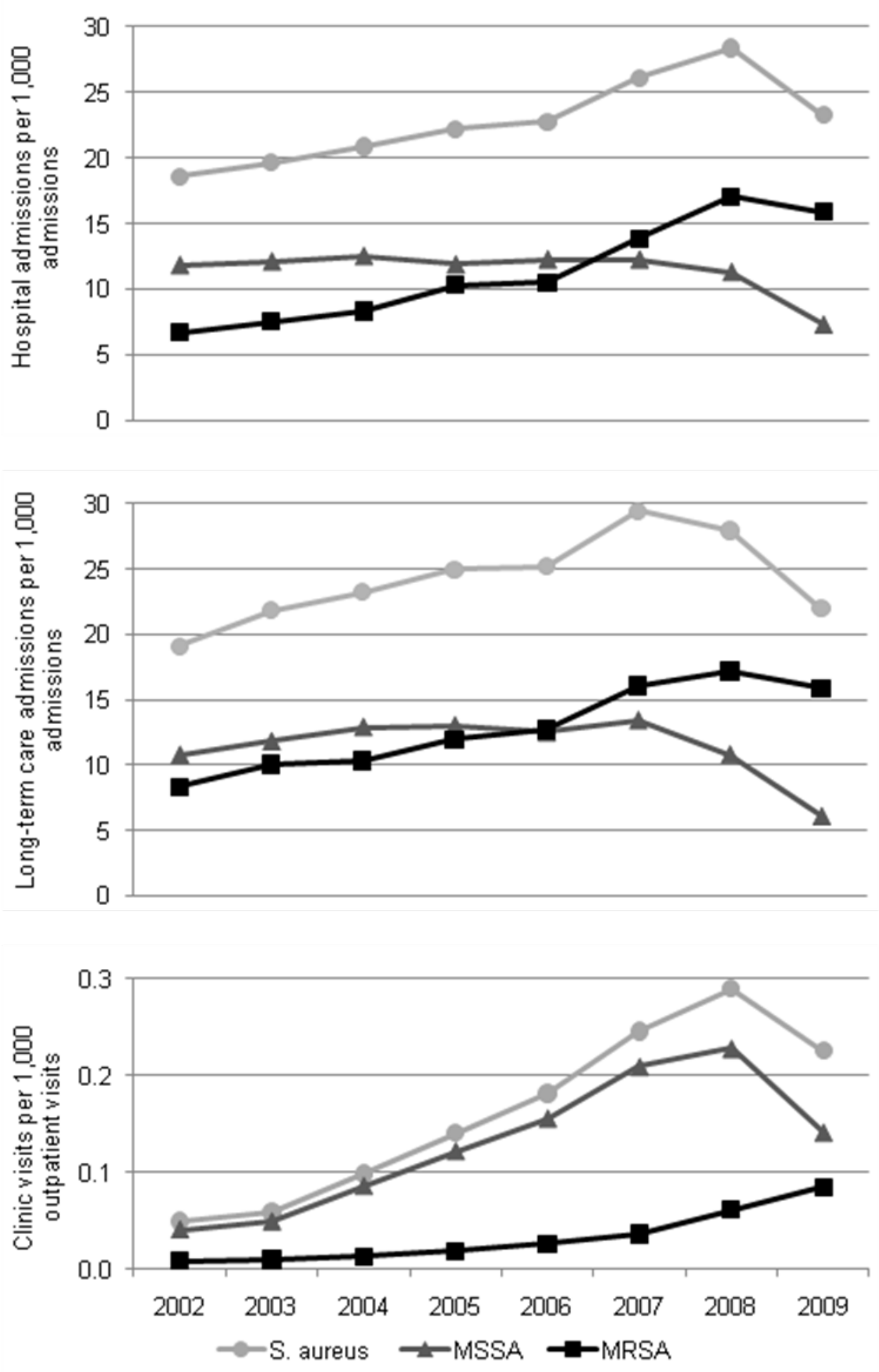
Fig 1 Incidence of Staphylococcus aureus (S. aureus), methicillin-susceptible S. aureus (MSSA), and methicillin-resistant S. aureus (MRSA) hospital admissions, long-term care admissions, and outpatient clinic visits per 1,000 admissions or visits in the Veterans Affairs Healthcare System, 2002-2009 